\section{Death to the Print Format-But Let Us Not Forget Our Past}

In his Commentary from the Presidential Team in the JanuaryFebruary 2015 issue, ${ }^{1}$ Glen Pearson announced that the Board of the Canadian Society of Hospital Pharmacists (CSHP) had decided to publish the Canadian Journal of Hospital Pharmacy (CJHP) in an electronic-only format, for reasons of cost. I for one will miss receiving a print copy of this journal as part of my membership in the CSHP. I am probably in the minority, as most of my colleagues will embrace the electronic-only format as a means of keeping membership fees as low as possible.

What concerns me is that the archives currently available online at the journal's website go back only to the year 2000. I hope that some of the money saved in not distributing a print version of the $C J H P$ will go toward expanding the online archives as far back in time as possible. When conducting online literature searches, it is an increasingly common source of frustration to find that significant, even landmark articles published many years ago are not available in their entirety in an electronic format. At best, you might be able to obtain an abstract. It is true that you can contact some publishers directly to request the full article, but this is not always convenient, and it is time-consuming. Fortunately, I work in a pharmacy department that has allowed me to keep back issues of the CJHP on hand, but I suspect this is not a common occurrence.

I hope this letter will stimulate the CSHP Board to make it a priority to expand the online $C J H P$ archives so that ready access to our past achievements will not be lost forever.

Reference

1. Pearson GJ. A new year-time for reconciliation. Can J Hosp Pharm. 2015; 68(1):96

\section{John Murdoch, BScPhm \\ Drug Information Service \\ Department of Pharmacy Services \\ Toronto General Hospital \\ University Health Network \\ Toronto, Ontario}

Competing interests: John Murdoch is a member of the Canadian Society of Hospital Pharmacists, which publishes the CJHP. No other competing interests were declared.

\section{[Glen Pearson replies:]}

I wish to thank John Murdoch for his interest in and support of the $C J H P$ and to acknowledge his concerns about the change to an electronic-only format for the journal (effective January 2015). As noted in my commentary, ${ }^{1}$ the Board's decision to publish CJHP in electronic-only format was deemed to represent an effective way to reconcile maintaining the journal's academic excellence and reputation as an international pharmacy publication with reducing the increasing economic burden associated with printing and mailing the hard-copy version, which falls on members of the CSHP. This decision is consistent with the trends of scholarly societies over the past 10 years or so, which have increasingly been moving away from print toward online-only journal subscriptions. ${ }^{2}$ As CSHP members are aware, $C J H P$ has been available in an online format, in addition to the print format, since 2009. It is notable that most academic libraries have been moving to an online-only environment for over a decade now. ${ }^{2}$ Given these trends and the goal of fiscal responsibility for the purpose of maintaining a viable and thriving society for CSHP members, the Board felt that, in 2015, the time was finally right to transition the journal to electronic-only format. It should be noted 
that for members like Mr Murdoch who "miss receiving a print copy of this journal", the downloadable and printable flipbook version that is available for each electronic issue (starting in 2015), looks just like the previous print copy.

Mr Murdoch also comments on the fact that CJHP's online archive extends only from 2000 to the present. I would like to first point out that online archiving is entirely separate from the decision to move to electronic-only format. Not surprisingly, the process of archiving back issues of the journal online is associated with a significant financial burden. Again, the decision of the Board to do (or, in this case, not do) something is always evaluated carefully in terms of both the opportunity costs and the benefits to CSHP members. An investment in archiving the pre-2000 issues of the journal can only occur when financial resources are available to fund this task without detriment to other CSHP programs and services that are considered important and valuable to members. In recent years, the CJHP Editorial Board has invested substantial energy into the process of preparing and applying for MEDLINE indexing of the journal. This focus has been viewed as paramount to the journal's achievement of its mission. Throughout this process, the CJHP Editorial Board has continued to ask the CSHP Board to have the remainder of the journal's back issues archived online. The CSHP Board is committed to ensuring that our journal achieves its mission, and the goal of having CJHP fully archived online, with all issues dating back to 1969, is also important and evaluated by the Board at regular intervals. We are currently exploring the logistic and financial implications associated with this step and anticipate moving toward completion of this project in the future!

I would like to reassure John Murdoch and all of our members that the CSHP Board will not forget the Society's past. Nonetheless, our attention to history, specifically through archiving of the journal, must be tempered with our need to focus on present needs and future advancements.

References

1. Pearson GJ. A new year-time for reconciliation. Can J Hosp Pharm. 2015; 68(1):96.

2. Meadows A. Moving scholarly society members online-only—are we reaching the tipping point? In: The scholarly kitchen [blog]. Wordpress.com; 2012 Dec 13 [cited 2015 Oct 12]. Available from: http://scholarlykitchen. sspnet.org/2012/12/13/moving-scholarly-society-members-online-only-arewe-reaching-the-tipping-point/

Glen J Pearson, BSc, BSCPhm, PharmD, FCSHP

President and External Liaison

Canadian Society of Hospital Pharmacists

Competing interests: Other than the author's position on the CSHP Board, no competing interests were declared.

\section{CISADL 2015}

\section{Order your copy of the 2015 Canadian Investigational \& Special Access Drug List today!}

\section{Please use the CSHP order form found online at CSHP.ca to place your order:}

$$
\text { http://www.cshp.ca/productsServices/otherPublications/canadianInvestigational_e.asp }
$$

The CISADL is a compilation of drugs that are currently not marketed in Canada and may have Investigational or Special Access status with Health Canada. This list is not endorsed by Health Canada's Special Access Program. For precise information about the regulatory status of a drug, contact the Special Access Program directly. Entries to the list are contributed to by several Drug Information Centers across Canada and by Canadian drug manufacturers. In cases where non-marketed drugs do not appear on the list, foreign references should be consulted. The content of the list includes generic name and strength/concentration, dosage form, pharmacology/therapeutic use, trade and code name, source (manufacturer/distributor), and comments. Available in English only.

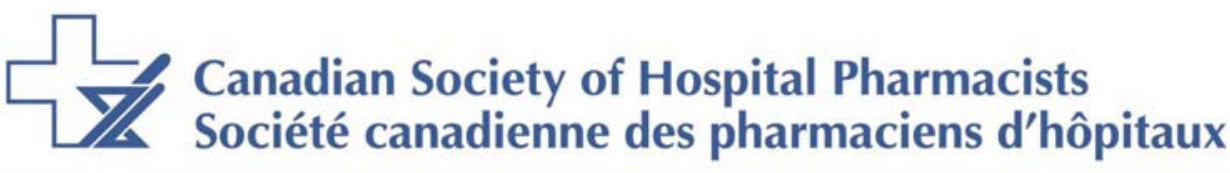

